\section{A problemática do uso de agrotóxicos no Brasil: a necessidade de construção de uma visão compartilhada por todos os atores sociais}

The problem of pesticide use in Brazil: The need of building a view shared by all social actors

Andrea Viviana Waichman ${ }^{1}$

O desempenho econômico excepcional do setor agrícola brasileiro fez o produto interno bruto (PIB) do país dobrar na última década. Considerando esta tendência, a Food and Agriculture Organization (FAO) e a Organization for Economic Cooperation and Development (OECD) estimam que o Brasil será, na próxima década, o maior produtor agrícola e o maior consumidor de agrotóxicos do mundo (ORGANIZATION FOR ECONOMIC COOPERATION AND DEVELOPMENT; FOOD AND AGRICULTURE ORGANIZATION OF THE UNITED NATIONS, 2010). Esse avanço se dá à custa de um modelo de desenvolvimento agrícola baseado no uso intensivo de insumos e recursos naturais cujo impacto se traduz em elevados custos ambientais e sociais. Isto nos coloca frente ao desafio de implementar não só uma agenda de pesquisa multidisciplinar que traga avanços no entendimento da problemática do uso de agrotóxicos no Brasil, mas principalmente na proposição de soluções que primem pela integração das componentes econômica, social e ambiental desta problemática. Este desafio se reveste de alta complexidade pelo caráter multidimensional da temática, pelos diferentes interesses que os setores envolvidos têm e as controversas visões sobre os benefícios e os danos que o uso de agrotóxicos produz.

Neste contexto, discutirei alguns entraves que precisam ser superados no intuito de contribuir para a construção de uma estratégia integrada de pesquisa que vai além da abordagem multidisciplinar acadêmica. Este novo paradigma implica no envolvimento de todos os atores sociais (indústria agroquímica, governo, produtores, trabalhadores rurais, pesquisadores, sociedade civil organizada) no entendimento da percepção que estes atores têm da problemática e na compreensão da racionalidade subjacente ao uso do agrotóxico no Brasil, incorporando múltiplas pers- pectivas no desenvolvimento de uma linguagem e de uma visão comum a todos.

A construção dessa visão compartilhada, necessária para a elaboração dessa agenda integrada de pesquisa, inicia-se com a análise do termo utilizado pelos diferentes setores para definir estas substâncias. Os termos "agrotóxicos" e "defensivos" revelam a percepção dos efeitos que o uso dessas substâncias causam, sendo para alguns benéficos, para outros, nefastos. Embora o termo agrotóxico seja uma categoria estabelecida em lei após a promulgação de diversas legislações estaduais e da Lei Federal $n^{\circ}$ 7.802/89 (BRASIL, 1989) [Lei dos Agrotóxicos], ainda prevalece uma visão dicotômica sobre estas substâncias. Enquanto no setor de saúde e meio ambiente são denominadas agrotóxicos, destacando seu caráter nocivo não somente para as pragas, mas fundamentalmente para a saúde e o ambiente, o setor agrícola as denomina defensivos agrícolas, uma vez que estas substâncias se constituem em um dos principais instrumentos utilizados nas estratégias de defesa agrícola e proteção dos cultivos, de forma a aumentar a produtividade e garantir a colheita. É interessante pensar que a percepção das indústrias é que elas criaram produtos para salvar a produção de alimentos e outros produtos indispensáveis à sociedade do ataque de pragas, entretanto, sem considerar que estes produtos hoje fazem parte de uma agricultura considerada insustentável. A indústria agroquímica e o setor agrícola parecem desprezar ou ignorar os efeitos dessa estratégia defensiva, que são perversos, pois, em médio e longo prazo, terminam reduzindo a produtividade, seja pela contaminação do solo, pelo desenvolvimento de resistência, pela eliminação de controladores naturais das pragas, pela eliminação dos polinizadores, entre outros.

A Lei dos Agrotóxicos e os decretos que a regulamentaram - Decreto $n^{\circ}$ 98.816/90 (BRASIL, 1990), Decreto $\mathrm{n}^{\mathrm{o}} 4.074 / 2002$ (BRASIL, 2002) e Decreto $\mathrm{n}^{\mathrm{o}}$ 5.981/2006 (BRASIL, 2006) -, apesar do avanço que representam para a proteção da saúde pública e do ambiente, não conseguiram surtir o efeito esperado (GARCIA; BUSSACOS; FISCHER, 2005). Como Porto e Soares destacam no artigo em debate, os instrumentos de comando e controle contidos nesta legislação têm sido pouco eficientes em garantir o uso correto dos agrotóxicos e em assegurar a proteção da saúde humana e ambiental. Segundo esses autores, isso é resultado não só da precariedade do sistema de fiscalização, mas também da constante interven-

${ }^{1}$ Doutora em Ciências Biológicas. Instituto de Ciências Biológicas e Centro de Ciências do Ambiente. Universidade Federal do Amazonas. Manaus, AM, Brasil. Contato: Avenida Rodrigo Otávio Jordão Ramos, 3.000, Setor Sul, Campus Universitário. CEP: 69077-000, Manaus, AM. E-mail: awaichman@gmail.com. 
ção das empresas agroquímicas e de agronegócios no processo de regulamentação, diminuindo a probabilidade de restrições ao uso dos agrotóxicos.

Por pressão dos agentes econômicos, diversas alterações foram realizadas no marco regulatório do uso de agrotóxicos para atender interesses privados em detrimento da sociedade. Com a justificativa de reduzir os custos de produção dos agrotóxicos e, consequentemente, os custos da produção agrícola e evitar o monopólio do mercado nacional por empresas estrangeiras, o processo de registro foi flexibilizado e simplificado (ASSOCIAÇÃO NACIONAL DOS DEFENSIVOS GENÉRICOS, 1998b; ASSOCIAÇÃO NACIONAL DE DEFESA VEGETAL, 2006). Assim, foi adotado o critério de equivalência, que simplifica o processo de registro, não havendo a necessidade de uma avaliação completa; incentiva o uso de produtos cujas patentes estão vencidas, sendo que estes produtos obsoletos são em geral de maior toxicidade e persistência no ambiente, e elimina prazos de validade do registro, resultando em um "registro permanente" (ASSOCIAÇÃO NACIONAL DOS DEFENSIVOS GENÉRICOS, 1998a; ASSOCIAÇÃO NACIONAL DOS DEFENSIVOS GENÉRICOS, 2011). Como cabe à indústria de agrotóxicos apresentar os laudos ecotoxicológicos e toxicológicos das substâncias a serem registradas, também houve pressão para que sejam apenas exigidos os laudos de periculosidade ambiental e toxicológica, e não os de uma avaliação integrada de riscos (ASSOCIAÇÃO NACIONAL DE DEFESA VEGETAL, 2009). A realização desta avaliação é considerada um processo caro e lento, que levaria a demoras desnecessárias no registro dos produtos, implicaria em barreiras para a entrada de pequenas empresas nacionais no mercado do agrotóxico e aumentaria o custo de produção dos agrotóxicos, custos estes que seriam repassados aos agricultores (ASSOCIAÇẪO NACIONAL DOS DEFENSIVOS GENÉRICOS, 1998b). Como resultado da ação de grupos que buscam o atendimento de interesses puramente econômicos, perdeu-se um mecanismo de controle essencial à proteção da saúde humana, dos ecossistemas e sua biodiversidade.

Um dos principais entraves à realização da avaliação de riscos no Brasil é a escassez ou mesmo ausência de dados toxicológicos e ecotoxicológicos gerados sob condições locais e reais de uso, além de dados epidemiológicos, uma vez que a obtenção destes dados demanda não só um grande volume de recursos, mas laboratórios bem estruturados e equipes científicas qualificadas. Estes dados poderiam ser gerados nas universidades e nos institutos de pesquisa com apoio das agências de fomento à pesquisa e desenvolvimento científico e tecnológico e dos ministérios que intervêm no processo de registro. Considerando que os dados sobre efeitos toxicológicos e ecotoxicológicos dos agrotóxicos devem ser apresentados pela indústria no momento do registro, é importante o financiamento de pesquisas independentes que, de alguma forma, possam validar ou contestar as informações apresentadas. Os resultados das pesquisas realizadas pela área ambiental e de saúde são fundamentais para subsidiar os processos de reavaliação dos agrotóxicos de forma a poder retirar do mercado produtos que representem riscos à saúde humana e ambiental. Alguns estudos mostram que as pesquisas realizadas ou financiadas pelas indústrias apresentaram mais resultados favoráveis (87\%) que as realizadas de forma independente $(40 \%)$ em relação à segurança e aos riscos dos agrotóxicos (FAGIN; LAVELLE, 1999; ANTONIOU et al., 2011). Embora o Brasil seja um dos maiores consumidores de agrotóxicos no mundo, verifica-se que a temática do uso de agrotóxicos e seus impactos na população e no ambiente não está incorporada à agenda do sistema de Ciência, Tecnologia e Inovação (CT\&I), sendo raramente considerada prioritária nas discussões sobre alocação de recursos, e tendo parcos investimentos para linhas de pesquisa sobre o tema, quando existentes.

Como mencionado anteriormente, a inserção de todos os atores numa agenda de pesquisa-ação requer o entendimento da racionalidade e da percepção que os diferentes atores têm do tema e que determina suas ações em relação aos agrotóxicos. Neste sentido, é interessante tornar os diversos atores em agentes ativos das pesquisas realizadas, das ações educativas e dos programas de controle e monitoramento. Embora extremamente influentes na hora de intervir no marco regulatório, estes agentes econômicos não têm colocado a mesma força em promover inovações e mudanças necessárias para a produção sustentável de alimentos. Isso se deve em parte pela visão que eles têm do que seja uma agricultura sustentável. Enquanto para alguns é aquela que otimiza os investimentos e maximiza lucros, para outros é aquela cuja produtividade a torna economicamente competitiva, pois a visão que eles têm da sustentabilidade é apenas econômica, esquecendo-se de que a sustentabilidade resulta de um tripé que inclui a equidade social e a conservação da qualidade ambiental e dos serviços ecossistêmicos.

Neste contexto e de forma a promover mudanças, é importante tentar compreender quais novas oportunidades existem para a indústria dos agrotóxicos numa agricultura mais sustentável e como a indústria está preparada para explorar esse potencial, com maiores investimentos em biotecnologia e manejo integrado de pragas. Deverá acontecer com as indústrias de agrotóxicos o que vem acontecendo com algumas indústrias petrolíferas, que aos poucos foram se transformando em empresas de energia, com forte investimento em energias renováveis e sustentáveis. Alguns alegam que a indústria deve procurar produtos de menor toxicidade ou persistência, embora, desde nossa perspectiva, isso não será suficiente e pouco contribuirá para uma agricultura mais sustentável, comprometida 
com a produção de alimentos saudáveis, com a proteção da saúde de agricultores e consumidores e com o ambiente no contexto do atual marco regulatório. Isto porque, não só no caso do Brasil, mas também em outros países menos desenvolvidos, agrotóxicos antigos com patentes vencidas conseguem ser produzidos e comercializados a custos e preços menores por empresas nacionais de pequeno porte e, portanto, tornam-se os favoritos principalmente dos agricultores familiares menos capitalizados (PESTICIDE ACTION NETWORK, 2006; SOARES; PORTO, 2009). Por outro lado, os testes realizados para o registro de novos produtos não necessariamente são capazes de evidenciar os efeitos crônicos do uso dos agrotóxicos, que podem aparecer dezenas de anos após seu lançamento no mercado e no ambiente.

Atribuir toda a responsabilidade pelos danos dos agrotóxicos às indústrias produtoras seria uma atitude ingênua, uma vez que os agricultores e a sociedade de forma mais ampla também têm uma parcela de responsabilidade. Nesta perspectiva, não podemos deixar de colocar que os produtores agrícolas, sejam eles patronais ou familiares, estão alinhados com a indústria agroquímica, porque ela tem um produto a oferecer que torna a lavoura mais produtiva e lucrativa. Por outro lado, os agricultores têm recebido pouca assistência do governo no sentido de reduzir sua dependência dos agrotóxicos e tornar a agricultura mais sustentável (MOREIRA et al., 2002; RECENA; CALDAS, 2008; WAICHMAN; EVEB; NINA, 2007). A adoção do agrotóxico como principal ferramenta de controle de pragas, em parte, foi promovida pelo próprio Estado a partir do sistema de assistência técnica e extensão rural implantado no Brasil.

Calcada no princípio de promover a modernização da agricultura no país, a extensão rural foi em grande parte responsável pela implantação de pacotes tecnológicos baseados na adoção do agrotóxico como estratégia de aumento de produtividade, inculcando nos agricultores a ideia de que a adoção desta tecnologia os tornaria agricultores modernos (KAGEYAMA, 2003; MIRANDA et al., 2007). A situação foi reforçada pelos programas de crédito agrícola que condicionavam sua concessão à aquisição de agrotóxicos, substituindo o papel do extensionista de garantir assistência técnica e fornecer orientação pelo papel de agente bancário, de forma a assegurar que os agricultores tivessem acesso ao crédito (GARCIA, 1996; KAGEYAMA, 2003). Somente os agricultores que aderiam ao credito rural recebiam a assessoria dos extensionistas. Mesmo assim, aqueles que não eram assistidos acabaram incorporando o pacote tecnológico num esquema informal de transferência tecnológica de agricultor-para-agricultor (GUIVANT, 1992). Entretanto, este sistema de transferência foi imperfeito, pois, geralmente, informações de cunho técnico, como os cuidados com a manipulação do produto e as forma adequadas de proteção da saúde e de redução dos riscos de envenenamento e contaminação ambiental, não eram repassadas. Ainda hoje, o conhecimento sobre o uso de agrotóxicos é baseado principalmente na própria experiência dos agricultores e na opinião dos revendedores do produto (WAICHMAN; EVEB; NINA, 2007). Assim, no cenário atual, a redução do uso de agrotóxicos e a transição para a agroecologia perpassam também por mudanças na extensão rural, que se deve renovar e inovar no cumprimento de sua missão. Neste sentido, espera-se que a Política e o Programa Nacional de Assistência Técnica e Extensão Rural para a Agricultura Familiar e Reforma Agrária - criados em 2010 pela Lei ํํำ 12.188 (BRASIL, 2010) - sejam importantes aliados, contribuindo para o desenvolvimento de uma agricultura sustentável, a segurança alimentar e a promoção da saúde e bem-estar do produtor e dos consumidores.

Ainda que o uso de agrotóxicos no Brasil esteja associado principalmente às culturas de exportação, como a soja, o algodão, a cana-de-açúcar, o tabaco e algumas frutas, produzidas no modelo do agronegócio, não podemos subestimar o uso que é feito pela agricultura familiar, hoje responsável pela produção de grande parte das frutas e hortaliças que consumimos (INSTITUTO BRASILEIRO DE GEOGRAFIA E ESTATÍSTICA, 2009). Assim, os efeitos do uso incorreto e abusivo dos agrotóxicos são transferidos diretamente para a mesa do consumidor final. O Programa de Análise de Resíduos de Agrotóxicos em Alimentos (PARA), da Agência Nacional de Vigilância Sanitária, criado em 2001 e que atualmente monitora 20 culturas em 25 unidades da Federação, reporta a cada ano as culturas nas quais os níveis de resíduos de agrotóxicos excederam os limites determinados pela legislação e a presença de agrotóxicos não autorizados para culturas específicas. Estes relatórios denunciam ainda a utilização de agrotóxicos proibidos no Brasil, que muitas vezes ingressam ilegalmente no país.

Na esfera do consumo, a sociedade tem sido bastante cética e passiva em questionar a segurança dos alimentos que consome e precisa ser adequadamente informada de forma a que possa se posicionar e participar mais ativamente do processo de controle de riscos alimentares. Não só é necessária uma maior preocupação dos consumidores com a qualidade dos alimentos ingeridos, mas também uma mudança de atitude, uma vez que a maioria deles exige produtos perfeitos, sem se preocupar que esta perfeição pode ser venenosa (SAABOR, 2003). Esta racionalidade é tão perversa que, na Amazônia, os agricultores borrifam as frutas e verduras com agrotóxicos após a colheita e quando estão encaixotadas e prontas para irem aos mercados com intuito de protegê-las de ataques de insetos e outras pragas que possam alterar suas qualidades estéticas e, portanto, reduzir seu preço (WAICHMAN et al., 2002; WAICHMAN; EVEB; NINA, 2007). 
Esta postura dos consumidores e as pressões do mercado têm feito com que os agrotóxicos sejam considerados essenciais na produção de alimentos. Da parte do agricultor, são percebidos como um elemento fundamental de segurança econômica frente às diversas incertezas que cercam a produção agrícola, principalmente do produtor menos capitalizado. Dentro desta percepção, a maioria dos agricultores aceita a primazia de possíveis riscos à saúde sobre o risco econômico associado às perdas da lavoura se não usar agrotóxicos (GUIVANT, 2001).

A aversão ao risco econômico é um dos fatores que leva os agricultores ao uso incorreto dos agrotóxicos e a ignorar os riscos à saúde (GUIVANT, 1994). É importante compreender esta visão conservadora para que se possa pensar em estratégias de uma possível transição agroecológica. É de se esperar que os agricultores se sintam pouco motivados a se envolver no processo de transição quando o custo de mudar para um modelo substitutivo dos agrotóxicos é elevado e quando as perdas que resultariam desta mudança constituem uma grande porcentagem das suas economias (WILSON; TISDELL, 2001). Neste sentido, como sugerido por Porto e Soares no artigo em debate, instrumentos econômicos devem ser implementados e podem se mostrar mais efetivos que os instrumentos de comando e controle, considerando a fragilidade dos sistemas de fiscalização e monitoramento. Assim, duas estratégias de incentivos econômicos, um negativo e um positivo, deveriam ser pensadas: a taxação destes insumos (princípio poluidor-pagador) e a implementação de subsídios para os produtores que utilizem manejo integrado de pragas e adotem práticas agroecológicas (princípio beneficiador-recebedor). Obviamente, ambas as estratégias estão permeadas de fragilidades pela resistência e pelas pressões contrárias da indústria em relação à sobretaxação e pela forma muito tímida com que o governo tem incentivado a agroecologia. No caso da taxação, medida considerada conservadora se comparada com uma política de proibição total, esta poderia ser relativa à toxicidade do produto, sendo que produtos mais tóxicos deveriam ter taxas maiores que produtos de menor toxicidade.

\section{Referências}

AGÊNCIA NACIONAL DE VIGILÂNCIA SANITÁRIA. Programa de Análise de Resíduos de Agrotóxicos em Alimentos (PARA). Disponível em: < http:// portal.anvisa.gov.br/wps/content/Anvisa+Portal/ Anvisa/Inicio/Agrotoxicos +e+Toxicologia/ Assuntos + de+Interesse/Programa +de+Analise +de+ Residuos + de + Agrotoxicos + em + Alimentos $>$. Acesso em: 23 jul. 2011.

ANTONIOU, M. et al. Roundup and birth defects: Is the public being kept in the dark? United Kingdom: Earth Open Source, jun. 2011. Disponível em: < http://
Como os custos desta taxação seriam repassados pelas indústrias aos agricultores, isto elevaria o preço dos agrotóxicos mais tóxicos, que pelo seu alto custo levaria os agricultores a procurarem alternativas economicamente menos onerosas. Simultaneamente, o subsídio às práticas agroecológicas reforçaria a mudança para modelos mais sustentáveis de agricultura. No entanto, as políticas de incentivos econômicos positivos para práticas protetoras do ambiente e da saúde humana são legalizadas apenas em alguns estados (ESPÍRITO SANTO, 2001; SANTA CATARINA, 2000). A recente Medida Provisória no 535, de 2 de junho de 2011 (BRASIL, 2011), que institui o Programa de Apoio à Conservação Ambiental e o Programa de Fomento às Atividades Produtivas Rurais, contempla exclusivamente famílias em situação de extrema pobreza, deixando de fora obviamente o agronegócio e os agricultores familiares que não se encontram nessa situação. Outras experiências, como o Programa de Desenvolvimento Socioambiental da Produção Familiar Rural - Proambiente (2004-2007), pioneiras em incentivar a produção sustentável, como protótipos de política pública, deixaram lições importantes que devem ser avaliadas e aprimoradas (SHIKI; SHIKI, 2011). Elementos estratégicos desse programa, como o fortalecimento das organizações sociais, a assessoria técnica e rural, o crédito rural diferenciado e o controle social, devem ser considerados para o sucesso de políticas governamentais de incentivo a sistemas produtivos que adotem os princípios da agroecologia.

A transição para uma agricultura agroecológica deve ser entendida como um processo gradativo em que diversas dificuldades deverão ser enfrentadas, uma vez que o agricultor, seja ele o grande produtor, seja o agricultor familiar, sente-se seguro com os agrotóxicos. Não deve ser deixado de lado que qualquer estratégia produtiva que o agricultor adote deve primar por maximizar a produção, de forma a atender as demandas da subsistência e do mercado e garantir alguma lucratividade. Caso contrário, fracassaremos mais uma vez.

farmandranchfreedom.org/sff/RoundupandBirthDefects. pdf $>$ Acesso em: 6 jun. 2012.

ASSOCIAÇÃO NACIONAL DE DEFESA VEGETAL. Simplificação ou agilização de registros? O que é melhor para o agronegócio brasileiro. Defesa Agrícola, São Paulo, ano 2, n. 5, ago. 2006. Disponível em: < http://www.andef.com.br/arquivos/defesa/Defesa3. pdf> . Acesso em: 23 jul. 2011.

. Pronunciamento sobre reavaliações. Defesa Agrícola, São Paulo, ano 5, n. 11, jun. 
2009. Disponível em: < http://www.andef.com. br/arquivos/defesa/Defesa11a.pdf $>$. Acesso em: 23/07/2011.

ASSOCIAÇÃO NACIONAL DOS DEFENSIVOS GENÉRICOS. Similaridade. [Editorial], São Paulo, out. 1998a. Seção Artigos, Informativos 1998-1999, n. 1. Disponível em: < http://www.aenda.com.br/ informativo_001.htm>. Acesso em: 25 jul. 2011.

. Alto custo para registrar defensivos genéricos. [Editorial], São Paulo, dez. 1998b. Seção Artigos, Informativos 1998-1999, n. 4. Disponível em: <http:// www.aenda.com.br/informativo_004.htm >. Acesso em: 25 jul. 2011.

. Equivalência constrói, reavaliação destrói. [Editorial], São Paulo, jan. 2011. Seção Artigos, Artigos 2011, s/n. Disponível em: < http://www.aenda.org.br/ new_artigos2011.htm>. Acesso em: 25 jul. 2011.

BRASIL. Lei no 7.802, de 11 de julho de 1989. Dispõe sobre a pesquisa, a experimentação, a produção, a embalagem e rotulagem, o transporte, o armazenamento, a comercialização, a propaganda comercial, a utilização, a importação, a exportação, o destino final dos resíduos e embalagens, o registro, a classificação, o controle, a inspeção e a fiscalização de agrotóxicos, seus componentes e afins, e dá outras providências. Diário Oficial [da] República Federativa do Brasil. Brasília, DF, 12 jul. 1989.

. Decreto nº 98.816, de 11 de janeiro de 1990. Regulamenta a Lei n⿳o 7.802, de 1989, que dispõe sobre a pesquisa, a experimentação, a produção, a embalagem e rotulagem o transporte, o armazenamento, a comercialização, a propaganda comercial, a utilização, a importação, exportação, o destino final dos resíduos e embalagens, o registro, a classificação, o controle, a inspeção e a fiscalização de agrotóxicos, seus componentes e afins, e dá outras providências. Diário Oficial [da] República Federativa do Brasil. Brasília, DF, 12 jan. 1990.

. Decreto $\mathrm{n}^{\circ} 4.074$, de 04 de janeiro de 2002 . Regulamenta a Lei $\mathrm{n}^{-}$7.802, de 11 de julho de 1989, que dispõe sobre a pesquisa, a experimentação, a produção, a embalagem e rotulagem, o transporte, o armazenamento, a comercialização, a propaganda comercial, a utilização, a importação, a exportação, o destino final dos resíduos e embalagens, o registro, a classificação, o controle, a inspeção e a fiscalização de agrotóxicos, seus componentes e afins, e dá outras providências. Diário Oficial [da] República Federativa do Brasil. Brasília, DF, 05 jan. 2002.

. Decreto no 5.981 , de 06 de dezembro de 2006. Dá nova redação e inclui dispositivos ao Decreto $n^{\circ} 4.074$, de 4 de janeiro de 2002, que regulamenta a Lei $\mathrm{n}^{\circ}$ 7.802, de 11 de julho de 1989, que dispõe sobre a pesquisa, a experimentação, a produção, a embalagem e rotulagem, o transporte, o armazenamento, a comercialização, a propaganda comercial, a utilização, a importação, a exportação, o destino final dos resíduos e embalagens, o registro, a classificação, o controle, a inspeção e a fiscalização de agrotóxicos, seus componentes e afins. Diário Oficial [da] República Federativa do Brasil. Brasília, DF, 07 dez. 2006.

Lei n⿳0 12.188, de 11 de janeiro de 2010. Institui a Política Nacional de Assistência Técnica e Extensão Rural para a Agricultura Familiar e Reforma Agrária - PNATER e o Programa Nacional de Assistência Técnica e Extensão Rural na Agricultura Familiar e na Reforma Agrária - PRONATER, altera a Lei nº. 8.666, de 21 de junho de 1993, e dá outras providências. Diário Oficial [da] República Federativa do Brasil. Brasília, DF, 12 jan. 2010.

. Medida Provisória no 535 , de 2 de junho de 2011, Institui o Programa de Apoio à Conservação Ambiental e o Programa de Fomento às Atividades Produtivas Rurais; altera a Lei $\mathrm{n}^{\mathrm{o}}$ 10.836, de 9 de janeiro de 2004, e dá outras providências. Diário Oficial [da] República Federativa do Brasil. Brasília, DF, 03 jun. 2011.

ESPIRITO SANTO (Estado). Lei nº 6.848, de 06 de novembro de 2001. Dispõe sobre a Política Estadual de Incentivo à Produção Agroecológica. Diário Oficial do Espírito Santo, Vitória, ES, 7 nov. 2001.

FAGIN, D.; LAVELLE, M. Toxic deception: how the chemical industry manipulates science, bends the law and endangers your health. Monroe, ME, USA: Common Courage Press, 1999.

GARCIA, E. G. Segurança e Saúde no trabalho rural com agrotóxicos: contribuição para uma abordagem mais abrangente. 1996. 211 f. Dissertação (Mestrado em Saúde Pública)-Faculdade de Saúde Pública, Universidade de São Paulo,. São Paulo: USP, 1996.

GARCIA, E. G.; BUSSACOS, M. A.; FISCHER, F. M. Impact of legislation on registration of acutely toxic pesticides in Brazil. Revista de Saúde Pública, São Paulo, v. 39, n. 5, p. 1-8, 2005.

GUIVANT, J. S. O uso de agrotóxicos e os problemas de sua legitimação. Um estudo de sociologia ambiental no Município de Santo Amaro da Imperatriz, SC. 1992. 387 f. Tese (Doutorado em Ciências Sociais)-Instituto de Filosofia e Ciências Humanas. Universidade Estadual de Campinas, Campinas: Unicamp, 1992.

. Percepção dos olericultores da Grande Florianópolis (SC) sobre os riscos decorrentes do uso de agrotóxicos. Revista Brasileira de Saúde Ocupacional, São Paulo, v. 22, n. 82, p. 47-57, 1994,

A agricultura sustentável na perspectiva das ciências sociais. In: VIOLA, E. J. et al. Meio Ambiente, desenvolvimento e cidadania. 3. ed. São Paulo: Cortez; Florianópolis: UFSC, 2001. p. 99-133.

INSTITUTO BRASILEIRO DE GEOGRAFIA E ESTATÍSTICA. Censo Agropecuário 2006. Agricultura Familiar. Primeiros Resultados. Rio de Janeiro: IBGE, 2009.

KAGEYAMA, A. Produtividade e renda na agricultura familiar: efeitos do PRONAF-crédito. Revista Agricultura em São Paulo, São Paulo, v. 50, n. 2, p. 1-13, 2003.

MIRANDA, A. C., et al. Neoliberalismo, uso de agrotóxicos e a crise da soberania alimentar no Brasil. 
Ciência e Saúde Coletiva, Rio de Janeiro, v. 12, n. 1, p. 7-14, jan./mar. 2007.

MOREIRA, J. C., et al. Avaliação integrada do impacto do uso de agrotóxicos sobre a saúde humana em uma comunidade agrícola de Nova Friburgo/RJ. Ciência e Saúde Coletiva, Rio de Janeiro, v. 7, n. 2, p. 299-311, 2002.

\section{ORGANIZATION FOR ECONOMIC COOPERATION} AND DEVELOPMENT; FOOD AND AGRICULTURE ORGANIZATION OF THE UNITED NATIONS.

Agricultural Outlook 2010-2019. Disponível em: < http:/ www.agri-outlook.org/dataoecd/13/13/45438527.pdf $>$. Acesso em: 20 jul. 2011.

PESTICIDE ACTION NETWORK. Growing sales of generic pesticides - profiting from the past. Pesticides News, v. 71, p. 8, mar. 2006.

RECENA, M. C. P.; CALDAS, E. D. Percepção de risco, atitudes e práticas no uso de agrotóxicos entre agricultores de Culturama, MS. Revista de Saúde Pública, São Paulo, v. 42, n. 2, p. 294-301, 2008.

SAABOR, A. Demandas e exigências do mercado brasileiro de frutas: comentários sobre resultados de pesquisas de mercado realizadas nos estados de São Paulo, Rio de Janeiro e Minas Gerais. In: MARTINS, D. S. Papaya Brasil: qualidade do mamão para o mercado interno. Vitória: Incaper, 2003. p. 69-76.
SANTA CATARINA (Estado). Lei nº 11.634, de 12 de dezembro de 2000. Dispõe sobre a Política Estadual de Incentivo à Produção Agroecológica. Diário Oficial de Santa Catarina, Florianópolis, SC, 12 dez. 2000.

SHIKI, S.; SHIKI, S. F. N. Os Desafios de uma Política Nacional de Pagamentos por Serviços Ambientais: lições a partir do caso do Proambiente. Sustentabilidade em Debate, Brasília, v. 2, n. 1, p. 99-118, jan./jun. 2011.

SOARES, W. L.; PORTO, M. F. S. Estimating the social cost of pesticide use: an assessment from acute poisoning in Brazil. Ecological Economics, Amsterdam, v. 68, n. 10, p. 2721-2728, 2009.

WAICHMAN, A. V. et al. Use and fate of pesticides in the Amazon State, Brazil: risk to human health and the environment. Environmental Science and Pollution Research. Heidelberg, v. 9, n. 6, p. 423-428. 2002.

WAICHMAN, A.V.; EVEB, E.; NINA, N. C. S. Do farmers understand the information displayed on pesticide product labels? A key question to reduce pesticides exposure and risk of poisoning in the Brazilian Amazon. Crop Protection, Amsterdam, v. 26, n. 4, p. 576-583, 2007.

WILSON, C.; TISDELL, C. Why farmers continue to use pesticides despite environmental, health and sustainability costs? Ecological Economics, Amsterdam, v. 39, n. 39, p. 449-462, 2001.

Recebido: 04/08/11

Aprovado: 27/04/12 